\title{
Honest signaling in mouse lemur vocalizations?
}

\author{
Claudia Fichtel $^{1,2}$ (D) Peter M. Kappeler ${ }^{1,3} \cdot$ Martine Perret $^{4} \cdot$ Elise Huchard $^{5}$. \\ Pierre-Yves Henry ${ }^{4}$
}

Received: 28 February 2021 / Accepted: 23 October 2021/Published online: 13 December 2021

(c) The Author(s) 2021

\begin{abstract}
Animal vocalizations may provide information about a sender's condition or motivational state and, hence, mediate social interactions. In this study, we examined whether vocalizations of gray mouse lemurs (Microcebus murinus) emitted in aggressive contexts (grunts, tsaks) co-vary with physical condition, which would underly and indicate honest signaling. We recorded calls from captive individuals that were subjected to a caloric restricted (CR) or ad libitum (AL) diet, assuming that individuals on an ad libitum dietary regime were in better condition. We analyzed 828 grunts produced by seven CR and nine AL individuals and 270 tsaks by eight CR and five AL individuals. Grunts consisted of two separate elements, with the $1^{\text {st }}$ element having more energy in higher frequencies than the $2^{\text {nd }}$ element. Body mass correlated negatively with acoustic features of grunts, and heavier individuals produced lower-frequency grunts. Acoustic features of grunts did not differ between sexes. Acoustic features of tsaks were predicted by neither body mass nor sex. However, tsaks produced by AL individuals were noisier than those of CR individuals. Hence, manipulation of body condition via dietary regimes affected acoustic features of calls given during aggression in different ways: acoustic features of grunts varied according to the rule of acoustic allometry, and can be considered as honest signals. Acoustic features of tsaks, however, varied according to motivational structural rules. Longitudinal studies are now indicated to examine whether intra-individual changes in body mass are also reflected in the acoustic structure of calls, allowing callers to signal more flexible variation in condition.
\end{abstract}

Keywords communication $\cdot$ honest signaling $\cdot$ acoustic allometry $\cdot$ motivational structural rules $\cdot$ vocalizations $\cdot$ primates $\cdot$ mouse lemurs

Handling Editor: Joanna Setchell

Claudia Fichtel

Claudia.fichtel@gwdg.de ${ }^{1}$

Extended author information available on the last page of the article 


\section{Introduction}

A central objective in animal communication research is to understand what information is conveyed in signals, and what function communication may serve during social interactions (Seyfarth \& Cheney 2003). Among a wide range of taxa, acoustic cues in vocal signals are associated with rather stable, long-term attributes of callers, such as individual or species identity, sex, age, kin, and body size (Charlton et al. 2020; Clarke et al. 2006; Ey et al. 2007; Fichtel 2014; Masters et al. 1995; Rendall et al. 1996; Ryan \& Brenowitz 1985; Zimmermann et al. 2000). In contrast, acoustic cues in vocalizations are also associated with more flexible attributes of the caller, such as their motivational (Fichtel et al. 2001; Fichtel and Hammerschmidt 2002, 2003; Scheumann et al. 2007) or physiological state (Barelli et al. 2013; Buesching et al. 1998; Charlton et al. 2010a; Semple et al. 2002; Zimmermann 1996), dominance status (Kitchen et al. 2003; Vannoni \& McElligott 2008), or fighting ability (Fischer et al. 2004; Reby and McComb 2003; Reby et al. 2005).

Fighting ability is often operationalized through body size, and it is well established that frequencies in vocalizations co-vary with body size across frogs, birds, and mammals (Bowling et al. 2017; Charlton \& Reby 2016; Fitch \& Hauser 1995; Garcia et al. 2018; Gingras et al. 2013; Hauser 1993; Wallschläger 1980). According to the rule of acoustic allometry, larger animals tend to produce lowerfrequency calls than smaller animals, because they have longer vocal tracts producing lower resonances and longer vocal folds oscillating at lower frequencies (Fitch 1997; Taylor \& Reby 2010). For example, among primates and carnivores, the fundamental frequency and the frequency with the maximum amplitude correlate negatively with body size (Bowling et al. 2017). Among primates, the fundamental frequency correlates negatively with body size and vocal fold length, but the latter predicts more precisely the fundamental frequency, indicating a potential for decoupling between larynx and body size (Garcia et al. 2018). Such a decoupling of larynx and body size has been documented in several mammalian species (Charlton \& Reby 2016). For example, the hypertrophied larynges in howler monkeys (Alouatta ssp.) allow them to produce much lower formant frequencies than expected for their body size (Dunn et al. 2015).

Acoustic cues that provide accurate information about animal attributes, such as body size, may convey honest information because only individuals in better condition are capable to bear any costs associated with signal production (Zahavi 1977). Accordingly, vocal performance has been suggested to reflect individual quality (Bradbury and Vehrencamp 2011). Since body mass reflects individual's fighting ability (Arnott and Elwood 2009; Jonart et al. 2007; Vieira and Peixoto 2013), acoustic correlates of these traits are biologically relevant for senders and receivers. For example, giant pandas (Ailuropoda melanoleuca), when they encounter and compete over estrous females, produce 'bleats' that encode cues about the caller's sex, age, and body size (Charlton et al. 2009). Playback experiments with bleats showed that males as well as females respond more strongly to calls indicating larger male size (Charlton et al. 2010b). Similarly, male red deer (Cervus elaphus) respond more strongly to acoustic 
features of roars that indicate larger size and better fighting ability (Reby et al. 2005). Finally, among anthropoid primates, sexual dimorphism in fundamental frequency is associated with variation in the mating system. It increases during evolutionary transitions towards polygyny and decreases with transitions towards monogamy, suggesting that low male fundamental frequencies signal condition and have evolved in response or in parallel to changes in the intensity of mating competition (Puts et al. 2016).

Many species experience periodic changes in body mass due to variable food availability in the lean versus the rich season, but little is known about how such changes are reflected in the acoustic structure of animal vocalizations and whether these dynamics represent flexible indicators of fighting ability. Mouse lemurs are a suitable study species for this question because they have to cope with low food availability and high climatic unpredictability in their natural environment in Madagascar (Dewar \& Richard 2007). During the dry season, the austral winter, mouse lemurs experience shortfalls in food availability and lose body mass accordingly (Dammhahn \& Kappeler 2008; Schmid and Kappeler 1998). However, seasonal body and tail fattening in combination with energy saving strategies such as torpor, which is photoperiodically controlled, enables them to face these unfavourable environmental conditions (Aujard et al. 1998; Schmid and Kappeler 1998; Vuarin et al. 2013). As a consequence, mouse lemurs experience fluctuations of about one third in body mass across winter and summer in both captivity and the wild (Perret and Aujard 2001; Schmid \& Kappeler 1998).

Moreover, mouse lemurs are sexually monomorphic, nocturnal, solitary foragers exhibiting an unusal mating system; they are polygnyandrous, and females are sexually receptive for only a few hours once a year (Eberle and Kappeler 2004a; Schmid \& Kappeler 1998). In the wild, body mass crucially impacts mating strategies of males, with heavier males having higher reproductive success (Eberle and Kappeler 2004b). In captivity, copulation success, however, is not influenced by body mass but by male competiveness and aggression (Gomez et al. 2012). In addition, females in better condition are more polyandrous than females in weaker condition, which might result in elevated genetic diversity or quality of offspring (Huchard et al. 2012; Jennions and Petrie 2000). Hence, signalling condition in acoustic displays during competition over and with mates might be beneficial for both sexes. Males may benefit by signalling condition to deter rival males but also to advertise quality to females, which preferentially mate with more competitive and aggressive males (Gomez et al. 2012). Since up to 14 males can solicit matings with an oestrous female, females may also benefit by signalling condition to deter unwanted mating attempts of males (Eberle and Kappeler 2004 a,b; Huchard et al. 2012).

During agonistic interactions, mouse lemurs produce grunts and tsaks and sometimes whistles. Grunts are considered as defensive threat calls, given during disturbances at their sleeping sites and during aggressive interactions (Leliveld et al. 2011; Zimmermann 2010). Tsaks are given during aggressive interactions with conspecifics but also during encounters with predators (Rahlfs \& Fichtel 2010; Zimmermann 2010). Whistles are harmonic calls that are given in several contexts and may serve to recruit conspecifics (Radespiel 2000; Rahlfs \& Fichtel 2010; Zimmermann 1996). 
During the mating season, mouse lemurs produce so-called trills that serve to attract mates. In males, calling rate of trills is associated with rank and may serve to advertise quality (Zimmerman 1996; Buesching et al. 1998). Hence, it is likely that also call types given during agonistic interactions may contain cues about the sender's quality. We, therefore, investigated whether caloric reduction influences acoustic features of vocalizations in gray mouse lemurs (Microcebus murinus). We recorded vocalizations given during agonistic contexts in captive mouse lemurs that were exposed to different dietary regimes, i.e., an ad libitum and caloric-restricted diet. These dietary restriction experiments were implemented to study the effect of caloric restriction on physiology, cognitive abilities, or female mating strategies (Canale et al. 2011; Giroud et al. 2008; Huchard et al. 2012). According to the rule of acoustic allometry, we predicted that mouse lemurs that were exposed to a dietary restriction, and, hence, assumed to be in a weaker condition, should produce higherfrequency calls than those exposed to an ad libitum diet. Since mouse lemurs are monomorphic, we did not predict that acoustic features co-vary with sex.

\section{Methods}

\section{Subjects}

Subjects were housed under standard breeding conditions in the breeding colony at the Muséum National d'Histoire Naturelle in Brunoy, France, IBISA platform, agreement E91.114.1, DDPP Essonne. Animals were kept with 14h of light and 10h of dark during the 6-month period of long days, and 10h of light and 14h of dark during the 6-month period of short days (Perret and Aujuard 2001). Animals were kept under two different feeding regimes: ad libitum (AL), where animals were fed with a homemade standard diet with a caloric value of $4.8 \mathrm{kJg}^{-1}$, containing $50 \%$ carbohydrates, $20 \%$ proteins, and $30 \%$ lipids. In the caloric-restricted (CR) regime, animals were exposed to a $80 \%$ caloric restriction with a daily food supply of $20 \%$ of the food mass offered to the group under the ad libitum regime (Giroud et al. 2008; Huchard et al. 2012). CR individuals were housed individually in cages (50 cm x $50 \mathrm{~cm} \times 50 \mathrm{~cm}$ ) with branches and two nest-boxes to control caloric intake. Studies of the short- and long-term effects of caloric restriction on the endocrine system and energy balance revealed that mouse lemurs have pronounced physiological flexibility, enabling them to adapt to acute food shortage (Giroud et al. 2008; Canale et al. 2011; Dal-Pan et al. 2011). Notably, the food-restricted individuals were not found to experience chronic stress, as urinary cortisol excretion (Canale et al. 2011) and plasma testosterone levels (Dal-Pan et al. 2011) remained unaffected by dietary treatment.

We recorded and analyzed the vocalizations of 25 individuals (13 AL and $12 \mathrm{CR}$, Table I) during mild disturbances at the sleeping box, i.e., when animals were taken out of their home cage in their sleeping box either for the cage to be cleaned or for their well-being to be inspected. During this procedure, we opened the door of the sleeping box to about one third of the full opening and positioned the microphone about $30 \mathrm{~cm}$ in front of it. 
Table I Individual identity, sex, diet, and number of calls analyzed in a study of mouse lemur vocalizations housed at the CNRS, MNHN, Brunoy (2010)

\begin{tabular}{|c|c|c|c|c|c|}
\hline \multirow[t]{2}{*}{ Diet } & \multirow[t]{2}{*}{ Sex } & \multirow[t]{2}{*}{ ID } & \multicolumn{2}{|l|}{$N$ grunts } & \multirow[t]{2}{*}{$N$ tsaks } \\
\hline & & & $1^{\text {st }}$ element & $2^{\text {nd }}$ element & \\
\hline $\mathrm{AL}$ & F & 1 & 27 & 26 & - \\
\hline AL & F & 4 & 30 & 30 & - \\
\hline $\mathrm{AL}$ & F & 5 & - & - & 6 \\
\hline AL & $\mathrm{F}$ & 6 & - & - & 19 \\
\hline $\mathrm{AL}$ & F & 7 & 28 & 18 & 18 \\
\hline AL & F & 8 & 20 & 17 & - \\
\hline $\mathrm{AL}$ & F & 12 & 20 & 11 & - \\
\hline $\mathrm{AL}$ & $\mathrm{F}$ & 13 & 29 & 16 & - \\
\hline $\mathrm{AL}$ & M & 16 & - & - & 30 \\
\hline $\mathrm{AL}$ & M & 18 & - & - & 21 \\
\hline $\mathrm{AL}$ & M & 20 & 27 & 22 & - \\
\hline $\mathrm{AL}$ & M & 21 & 22 & 12 & - \\
\hline $\mathrm{AL}$ & M & 22 & 27 & 7 & - \\
\hline $\mathrm{CR}$ & $\mathrm{F}$ & 2 & 53 & 51 & 14 \\
\hline CR & $\mathrm{F}$ & 3 & 23 & 23 & - \\
\hline $\mathrm{CR}$ & $\mathrm{F}$ & 9 & 41 & 35 & 15 \\
\hline $\mathrm{CR}$ & $\mathrm{F}$ & 10 & 23 & 21 & 31 \\
\hline $\mathrm{CR}$ & $\mathrm{F}$ & 11 & 54 & 45 & - \\
\hline CR & M & 14 & - & - & 30 \\
\hline $\mathrm{CR}$ & M & 15 & - & - & 24 \\
\hline CR & M & 17 & - & - & 24 \\
\hline $\mathrm{CR}$ & M & 19 & - & - & 25 \\
\hline $\mathrm{CR}$ & $\mathrm{M}$ & 23 & 20 & 15 & - \\
\hline $\mathrm{CR}$ & M & 24 & 23 & 12 & - \\
\hline CR & $\mathrm{M}$ & 25 & - & - & 13 \\
\hline
\end{tabular}

Some individuals were related, with a maternal relatedness coefficient ranging from 0.125 to 0.5 . For grunts, two of 36 dyads were related in the AL condition, whereas none of the dyads $(n=28)$ was related in the CR condition. For tsaks, two of ten dyads were related in the AL condition, whereas only three of 36 dyads were related in the CR condition. Since only a few dyads were related, we did not control for relatedness in the statistical analyses.

\section{Recordings and acoustic analyses}

We recorded vocalizations with an ultrasound microphone (polarized condenser microphone CMPA, Avisoft, Germany) in combination with an Avisoft-UltraSoundGate 116 (Avisoft, Germany) recording device resulting in a frequency range of $20-200 \mathrm{kHz}$; this was connected to a Toshiba Satellite Pro laptop (Toshiba Europe GmbH, Germany) with 'AVISOFT-RECORDER v.2.96" 
software (Avisoft, Germany). We digitized call recordings with a sampling rate of $500 \mathrm{kHz}$ at 16 bit resolution and converted them into spectrograms with 1024point fast Fourier transforms (window function: Hanning, 93.75\% overlap; time resolution: $0.64 \mathrm{~ms}$; frequency range: $100 \mathrm{kHz}$ ) using AVISOFT-SASLab Pro 4.2 (Avisoft, Germany). We visually inspected and sampled only calls of good quality and low background noise for acoustic analysis. We derived acoustic variables from frequency-time spectra with a time resolution of $5 \mathrm{~ms}$ for each time window across the call, using LMA 9.2, a custom software tool to extract different sets of variables from acoustic signals (Schrader \& Hammerschmidt 1997).

To avoid potential effects of a group-signature in the acoustic structure of vocalizations, we recorded vocalizations from AL individuals that were housed in different groups, and from CR individuals that were kept in individual cages in different rooms. Mouse lemurs produced three different call types during these mild disturbances: grunts, tsaks, and whistles. Grunts are noisy low-frequency calls, that consist of two clearly separated elements which are usually uttered together, but sometimes mouse lemurs produce only the first element (Fig. 1a). Therefore, we digitized and analyzed the two elements separately, referring to them as the $1^{\text {st }}$ and $2^{\text {nd }}$ elements of grunts. Tsaks are harmonic calls which are commonly described as chevron-shaped, because they increase in frequency, up to a local peak, followed by a decrease in frequency (Fig. 1b). Whistles are harmonic calls that are given in several contexts and may serve to recruit conspecifics in the mating season, when meeting members of sleeping associations at the sleeping site (Radespiel 2000), or during an escalating predator encounter to recruit other individuals to mob the predator (Rahlfs and Fichtel 2010). Since only a few individuals produced whistles $(n=6)$, we did not include them in the analysis.
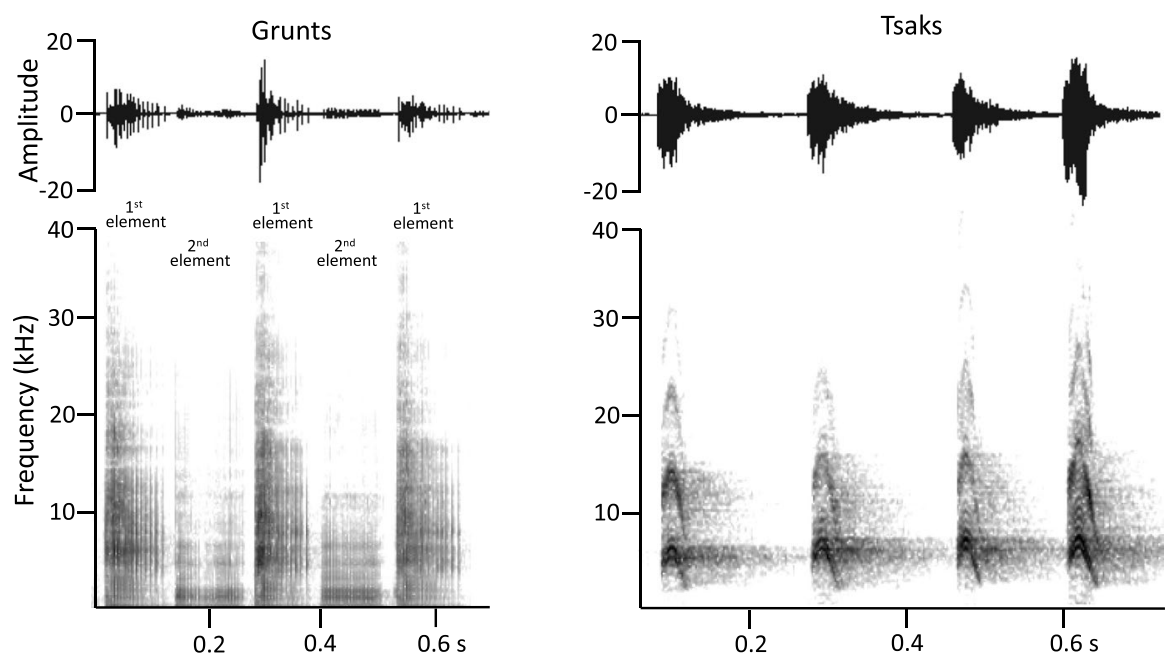

Figure 1 Spectrograms and oscillograms of grunts and tsaks of mouse lemurs housed at the CNRS, MNHN, Brunoy (2010). For grunts, two examples of calls with the $1^{\text {st }}$ and $2^{\text {nd }}$ element and one example with only the $1^{\text {st }}$ element are shown. 
To characterize the acoustic structure of grunts and tsaks (Fig. 1a, b), we measured acoustic variables that characterize the general call structure and are comparable with acoustic variables measured in other studies characterizing the structure of mammalian vocalizations (Fichtel and Hammerschmidt 2002; Fichtel et al. 2005; Manser 2001). Since the fundamental frequency can only be measured for vocalizations that are produced by regular vocal fold vibration, we could not measure it in grunts. Because tsaks are noisy calls that also contain harmonic energy, we could only measure the fundamental frequency reliably in 83 of 270 calls. Instead, we measured the frequency with the maximum amplitude (peak frequency) for both calls, which has been suggested to be associated with body size in several primates and carnivores (Bowling et al. 2017).

For each element of grunts, we measured the duration, the mean frequency range, the mean peak frequency, and the mean lower, central, and upper frequency distribution, as well as the mean $2^{\text {nd }}$ dominant frequency band (Table II). To characterize the acoustic structure of tsaks, we also measured the duration, the mean frequency range, and the mean peak frequency. Because tsaks have a narrow frequency bandwidth, we measured only the mean central frequency but included measurements of the start, end, and maximum of the central frequency to characterize the chevron-shaped acoustic structure of these calls. Because tsaks are noisy calls containing harmonic elements, we also measured the percentage of noisy parts in the call (Table II).

\section{Statistical analyses}

Because some individuals produced only grunts or tsaks and some produced both call types, we used a Fisher exact test to investigate whether the number of individuals producing either only one call type or both varies as a function of the dietary regime. We tested for differences in body mass of individuals exposed to the two dietary regimes with an exact Mann-Whitney U test.

To summarize multiple acoustic variables of a call into a single composite index, we first ran a principal component analysis (PCA) using the package "rela" (Chajewski 2009). We included only acoustic variables that describe the distribution of frequencies and not the duration of calls and log-transformed values of the acoustic variables. The PCAs were justified as shown by the Kaiser-Meyer-Olkin measure of sampling adequacy (grunts: $\mathrm{KMO}=0.82$; tsaks: $\mathrm{KMO}=0.80$ ) and Bartlett's test of sphericity (grunts: $p<0.01$; tsaks: $p<0.001$ ).

To estimate the influence of body mass, sex and call element ( $1^{\text {st }}$ and $2^{\text {nd }}$ element) on variation in the acoustic structure of grunts, we fitted two linear mixed models (LMMs) with either the first (PC1) or second (PC2) extracted principal component as the response variable using the packages "Ime4" and "ImerTest" (Bates et al. 2015; Kuznetsova et al. 2017). We fitted body mass, sex, and call element as fixed factors, individual identity as a random intercept effect, and a random slope of call element (Schielzeth and Forstmeier 2009; Barr et al. 2013).

To estimate the influence of body mass and sex on variation in the acoustic structure of tsaks, we fitted another two LMMs with PC1 or PC2 as the response 


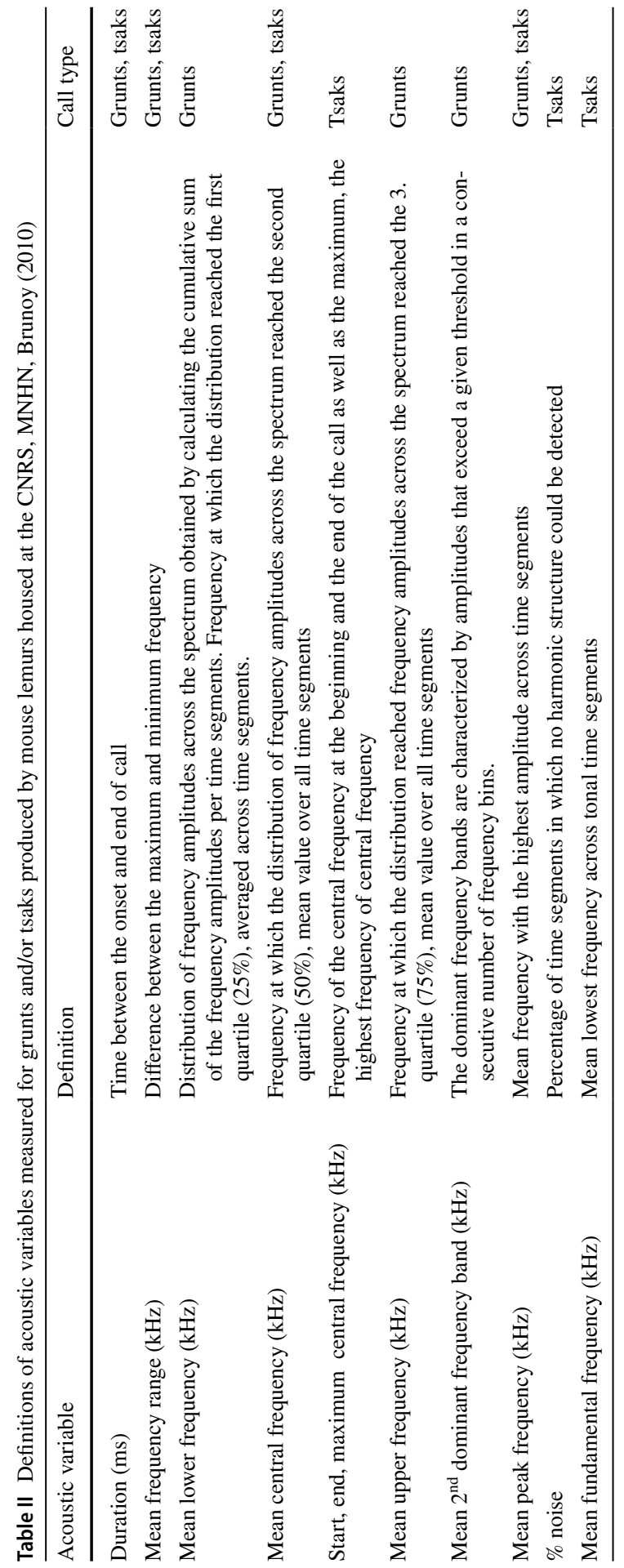


variable, body mass, and sex as fixed factors and individual identity as random factor. For calls in which we could measure the fundamental frequency, we calculated the mean and correlated it with body mass using a Spearman rank correlation. Since we could not include body mass and diet in the same model because they were collinear, we fitted four additional models for grunts and tsaks, including diet instead of body mass. We estimated the effect of diet per se because in another study, caloric-restricted females mated only with one male, whereas ad libitum-fed females mated with several males (Huchard et al. 2012). Since mating is costly and body mass loss during mating correlated with the number of mating partners (Huchard et al. 2012), caloric-restricted females might be less likely to engage in energetic costly behavior, such as displaying aggression during disturbances. In these models, we set either PC1 or PC2 as response variable, diet and sex as fixed factors, individual identity as random factor, and call element as random slope for models on acoustic variation of grunts. Following Perneger (1998), we did not apply corrections for multiple testing.

We conducted all statistical tests in $\mathrm{R}$ (version 4.0.3; R Core Team 2020). For all models (LMM), we checked the assumptions of normality distributions and homogeneity by visual inspection of a QQ-plot of residuals and residuals plotted against fitted values (Queen et al. 2002). We assessed model stability through the level of estimated coefficients and standard deviations (Nieuwenhuis et al. 2012). Furthermore, we checked collinearity issues by deriving variance inflation factors (VIF) (Fox and Weisberg 2019) of the standard linear model lacking the random effects. To test the significance of the predictors as a whole, we compared the fit of the full model with that of the null model comprising only the random factor and the intercept (Forstmeier and Schielzeth 2011).

\section{Ethical note}

This study adhered to the Guidelines for the Treatment of Animals in Behavioral Research and Teaching (Animal Behaviour 2020) and the legal requirements of the country (France) in which the work was carried out. All the procedures were carried out in accordance with the European Communities Council Directive (86/609/EEC) and were done by authorized experimenters (license numbers 91-439 and 91-455 delivered by the departmental veterinary service). Animal housings were equipped with foliage, branches, and several nest-boxes. Caloric restriction over a short period is physiologically sustainable for mouse lemurs and does not induce chronic stress (cortisol release), because mouse lemurs are adapted to drastic temporal changes in energy availability (Canale et al. 2011). The authors declare that they have no conflict of interest.

Data availability The datasets generated and analysed during the current study are not publicly available due to further analyses, but are available from the corresponding author on reasonable request. 


\section{Results}

In the AL condition, eight individuals produced only grunts, four only tsaks, and one individual both call types, whereas in the CR condition four individuals produced only grunts, five only tsaks, and three both call types. The number of individuals giving either only one call type, tsaks or grunts, or both did not differ between the dietary regimes (Fisher exact test: $p=0.32$ ). Individuals exposed to the CR diet had a lower body mass than those exposed to the AL diet (exact Mann-Whitney U-test: $\mathrm{Z}=1.32, p<0.001$, mean body mass $\pm \mathrm{SD}: \mathrm{CR}=76.2 \pm 17.5 \mathrm{~g}, \mathrm{AL}=99.6$ $\pm 10.4 \mathrm{~g})$.

\section{Grunts}

We analyzed 828 calls $\left(1^{\text {st }}\right.$ element $=467,2^{\text {nd }}$ element $\left.=361\right)$ produced by nine AL and seven CR individuals. Measurements of acoustic variables are presented in Table III.

The PCA extracted two principal components with Eigenvalues higher than 1, which explained in total $85 \%$ of the variance $(\mathrm{PC} 1=68 \%, \mathrm{PC} 2=17 \%)$. PC1 correlated most strongly with variables characterizing the general energy distribution of the calls (Table IV), with higher values of the PC1 characterizing calls that had a higher peak, central, lower and upper frequency and a broader frequency range. The $2^{\text {nd }}$ dominant frequency band loaded most strongly on PC2, with higher values characterizing higher pitched calls (Table IV).

Overall, the model investigating variation in the PC1 of grunts with regard to body mass, sex, and call element was significant (likelihood ratio test comparing full-null model comparison: $\chi^{2}=39.1$, df $\left.=3, p<0.001\right)$. PC1 correlated

Table III Acoustic variables measured in grunts and tsaks in a study of mouse lemur vocalizations housed at the CNRS, MNHN, Brunoy (2010).

\begin{tabular}{|c|c|c|c|}
\hline \multirow{2}{*}{$\begin{array}{l}\text { Acoustic variables } \\
(\text { mean } \pm S D)\end{array}$} & \multicolumn{2}{|l|}{ Grunts } & \multirow[t]{2}{*}{ Tsaks } \\
\hline & $1^{\text {st }}$ element & $2^{\text {nd }}$ element & \\
\hline Duration (ms) & $75.01 \pm 24.23$ & $106.45 \pm 53.02$ & $54.11 \pm 19.44$ \\
\hline Frequency range $(\mathrm{kHz})$ & $35.50 \pm 11.07$ & $14.87 \pm 6.05$ & $30.05 \pm 7.14$ \\
\hline Mean peak frequency $(\mathrm{kHz})$ & $2.76 \pm 3.82$ & $0.74 \pm 0.2$ & $18.75 \pm 2.84$ \\
\hline Mean lower frequency $(\mathrm{kHz})$ & $5.94 \pm 4.41$ & $1.05 \pm 0.53$ & - \\
\hline Mean upper frequency $(\mathrm{kHz})$ & $22.16 \pm 5.03$ & $8.54 \pm 4.02$ & - \\
\hline Mean $2^{\text {nd }}$ dominant frequency band $(\mathrm{kHz})$ & $14.89 \pm 2.77$ & $13.66 \pm 3.51$ & - \\
\hline Mean central frequency $(\mathrm{kHz})$ & $13.68 \pm 5.17$ & $2.98 \pm 1.91$ & $20.54 \pm 2.66$ \\
\hline Start central frequency $(\mathrm{kHz})$ & - & - & $19.41 \pm 2.79$ \\
\hline End central frequency $(\mathrm{kHz})$ & - & - & $18.67 \pm 2.57$ \\
\hline Maximum central frequency $(\mathrm{kHz})$ & - & - & $23.31 \pm 3.28$ \\
\hline Noise $\%$ & - & - & $91.27 \pm 11.61$ \\
\hline
\end{tabular}


Table IV Loadings of each variable on the first (PC1) and second (PC2) principal component for each acoustic variable measured in grunts and tsaks in a study of mouse lemur vocalizations housed at the CNRS, MNHN, Brunoy (2010)

\begin{tabular}{|c|c|c|c|c|}
\hline \multirow[t]{2}{*}{ Acoustic variables } & \multicolumn{2}{|c|}{ Grunts } & \multicolumn{2}{|c|}{ Tsaks } \\
\hline & $\mathrm{PC} 1$ & PC2 & $\mathrm{PC} 1$ & PC2 \\
\hline Mean frequency range & 0.48 & -0.01 & 0.36 & 0.28 \\
\hline Mean peak frequency & 0.36 & -0.10 & 0.43 & -0.19 \\
\hline $\begin{array}{l}\text { Mean } 2^{\text {nd }} \text { dominant frequency } \\
\text { band }\end{array}$ & 0.03 & 0.99 & - & - \\
\hline Mean lower frequency & 0.47 & -0.08 & - & - \\
\hline Mean upper frequency & 0.44 & 0.10 & - & - \\
\hline Mean central frequency & 0.48 & 0.01 & 0.48 & 0.06 \\
\hline Start central frequency & - & - & 0.35 & 0.23 \\
\hline End central frequency & - & - & 0.39 & -0.27 \\
\hline Maximum central frequency & - & - & 0.41 & 0.21 \\
\hline Noise & - & - & 0.13 & -0.84 \\
\hline$\%$ of variance explained & 68 & 17 & 59 & 16 \\
\hline
\end{tabular}

negatively with body mass, with grunts produced by heavier individuals having more energy in lower frequencies than calls produced by lighter individuals (Table IVa, Fig 2). PC1 co-varied significantly with call element. The $1^{\text {st }}$ element of grunts had more energy in higher frequencies than the $2^{\text {nd }}$ element.

The model investigating the influence of body mass, sex, and call element on variation of the PC2 of grunts was also significant (likelihood ratio test comparing full-null model comparison: $\chi^{2}=10.8$, df $=3, p=0.013$ ). PC2 differed significantly between call elements, with the $1^{\text {st }}$ element containing more energy

Figure 2 Values of the PC1 $\left(1^{\text {st }}\right.$ principal component) plotted against body mass for both call elements of grunts recorded in a study of mouse lemur vocalizations housed at the CNRS, MNHN, Brunoy (2010). Dashed lines indicate the regression lines and confidence intervals for the $1^{\text {st }}$ element in grey and the $2^{\text {nd }}$ element in turquoise.

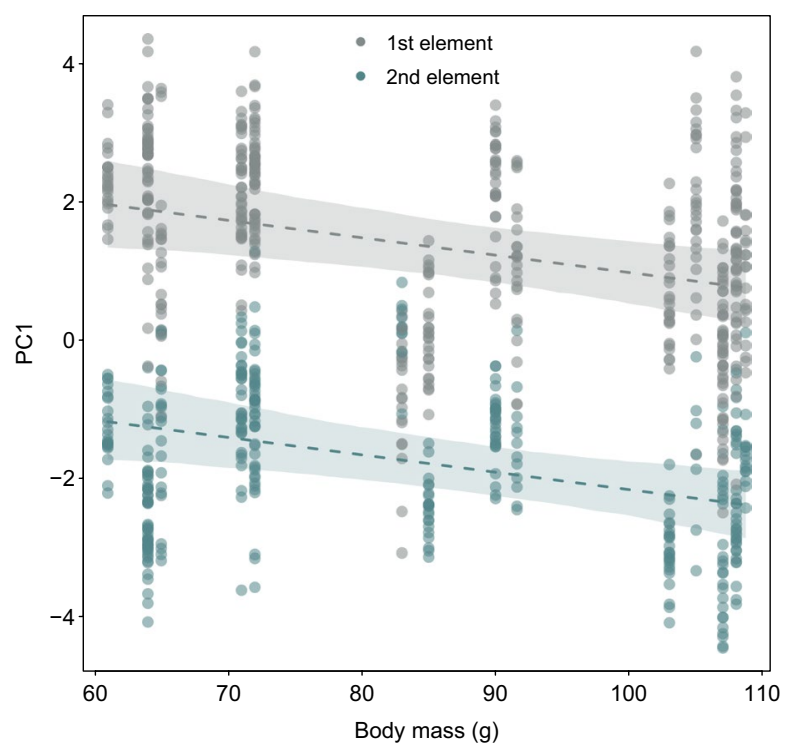


in higher frequencies than the $2^{\text {nd }}$ element (Table Vb). Variation in PC2 co-varied only by trend ( $p=0.07$ ) with body mass, and did not co-vary with sex (Table Vb).

The model estimating the influence of diet, sex, and call element on variation in PC1 was significant (likelihood ratio test comparing full-null model comparison: $\chi^{2}=37.7$, df $=3, p<0.001$; Table Vc). Diet and call element significantly influenced variation in PC1. AL individuals that were heavier produced grunts that had lower PC1 values, and the $1^{\text {st }}$ element had more energy in higher frequencies than the $2^{\text {nd }}$ element. The model estimating the influence of diet, sex, and call element on variation in PC2 was also significant (likelihood ratio test comparing full-null model comparison: $\chi^{2}=8.52$, df $=3, p=0.037$; Table Vd). Call element but not diet or sex influenced variation in PC2.

\section{Tsaks}

We analyzed 270 calls given by five AL and eight CR individuals. Measurements of acoustic variables are presented in Table III. The first two principal components of the PCA had eigenvalues higher than 1, which explained $75 \%$ of the variance in total $(\mathrm{PC} 1=59 \%, \mathrm{PC} 2=16 \%)$. Similar to grunts, the PC1 of tsaks correlated most strongly with variables characterizing the general energy distribution within calls (Table IV), with higher values of the PC1 characterizing calls that had a higher start, end, maximum, and mean lower frequency, and a higher mean

Table V Results of LMMs testing the influence of body mass, diet, call element and sex on variation in PC1 and PC2 $\left(1^{\text {st }}\right.$ and $2^{\text {nd }}$ principal component; $n=836 ; \mathrm{N}_{\mathrm{ID}}=16$ ) of grunts in a study of mouse lemur vocalizations housed at the CNRS, MNHN, Brunoy (2010). We tested body mass and diet in separate models due to collinearity.

\begin{tabular}{|c|c|c|c|c|}
\hline Response variable & Term & Est & SE & $P$ \\
\hline \multirow[t]{4}{*}{ a) $\mathrm{PC} 1$} & Intercept & 3.37 & 0.88 & $\mathrm{~b}$ \\
\hline & Body mass & -0.03 & 0.01 & 0.021 \\
\hline & Call element (2nd) ${ }^{a}$ & -3.02 & 0.31 & $<0.001$ \\
\hline & Sex (male) ${ }^{a}$ & -0.26 & 0.36 & 0.488 \\
\hline \multirow[t]{4}{*}{ b) $\mathrm{PC} 2$} & Intercept & -1.01 & 0.65 & $\mathrm{~b}$ \\
\hline & Body mass & 0.02 & 0.01 & 0.063 \\
\hline & Call element (2nd) ${ }^{a}$ & -0.50 & 0.16 & 0.007 \\
\hline & Sex $(\text { male })^{a}$ & -0.27 & 0.28 & 0.347 \\
\hline \multirow[t]{4}{*}{ c) $\mathrm{PC} 1$} & Intercept & 0.85 & 0.30 & $\mathrm{~b}$ \\
\hline & Diet & 0.81 & 0.34 & 0.035 \\
\hline & Call element $(2 \mathrm{nd})^{\mathrm{a}}$ & -3.02 & 0.31 & $<0.001$ \\
\hline & Sex (male) ${ }^{a}$ & -0.03 & 0.37 & 0.943 \\
\hline \multirow[t]{4}{*}{ d) PC1 } & Intercept & 0.25 & 0.22 & $\mathrm{~b}$ \\
\hline & Diet & 0.08 & 0.27 & 0.768 \\
\hline & Call element $(2 \mathrm{nd})^{\mathrm{a}}$ & -0.51 & 0.16 & 0.007 \\
\hline & Sex $(\text { male })^{a}$ & -0.16 & 0.29 & 0.598 \\
\hline
\end{tabular}

a 1st element and females as reference categories

${ }^{\mathrm{b}}$ Not shown as has no meaningful interpretation

Bold indicates $p<0.05$. 
Table VI Results of LMMs testing the influence of body mass, diet, call element and sex on variation in PC1 and PC2 $\left(1^{\text {st }}\right.$ and $2^{\text {nd }}$ principal pomponent; $n=272 ; \mathrm{N}_{\mathrm{ID}}=15$ ) of tsaks in a study of mouse lemur vocalizations housed at the CNRS, MNHN, Brunoy (2010). We tested body mass and diet in separate models due to collinearity

\begin{tabular}{|c|c|c|c|c|}
\hline Response variable & Term & Est & SE & $P$ \\
\hline \multirow[t]{3}{*}{ a) PC1 } & Intercept & -1.45 & 2.95 & $\mathrm{~b}$ \\
\hline & Body mass & 0.02 & 0.02 & 0.432 \\
\hline & Sex $(\text { male })^{a}$ & -0.85 & 0.91 & 0.398 \\
\hline \multirow[t]{3}{*}{ b) $\mathrm{PC2}$} & Intercept & 0.04 & 0.68 & $\mathrm{~b}$ \\
\hline & Body mass & -0.01 & 0.01 & 0.591 \\
\hline & Sex (male) ${ }^{a}$ & 0.58 & 0.34 & 0.112 \\
\hline \multirow[t]{3}{*}{ c) PC1 } & Intercept & 0.12 & 0.81 & $\mathrm{~b}$ \\
\hline & $\operatorname{Diet}(\mathrm{CR})^{\mathrm{a}}$ & -0.11 & 0.93 & 0.906 \\
\hline & Sex (male) ${ }^{a}$ & -0.46 & 0.91 & 0.621 \\
\hline \multirow[t]{3}{*}{ d) $\mathrm{PC2}$} & Intercept & -0.67 & 0.21 & $\mathrm{~b}$ \\
\hline & $\operatorname{Diet}(\mathrm{CR})^{\mathrm{a}}$ & 0.68 & 0.24 & 0.016 \\
\hline & Sex (male) ${ }^{a}$ & 0.38 & 0.23 & 0.130 \\
\hline
\end{tabular}

${ }^{a}$ sex and dietary regime: males and ad libitum (AL) as reference categories

${ }^{\mathrm{b}}$ Not shown as has no meaningful interpretation

Bold indicates $p<0.05$.

central and peak frequency. PC2 loaded most strongly with noise, with higher values characterizing calls that were less noisy (Table IV).

The models investigating the influence of body mass and sex on variation of the PC1 and PC2 of tsaks were not significant (likelihood ratio test comparing full-null model comparison: PC1: $\chi^{2}=1.25$, df $=2, p=0.530$, PC2: $\chi^{2}=3.43$, df $=2, p$ $=0.180$; Table VIa, b). In the subset of calls $(n=83)$ for which we could measure the fundamental frequency, body mass did not correlate with the mean fundamental frequency (Spearman rank, $n=11, R=-0.24, p=0.484$ ). This result should be considered carefully, however, because we could only measure the fundamental frequency in one call in three of eleven individuals.

PC1 co-varied neither with diet or sex (likelihood ratio test comparing full-null model comparison: $\chi^{2}=0.42$, $\mathrm{df}=2 p=0.810$; Table VIc). PC2, however, had lower values in tsaks given by AL individuals than by CR individuals (likelihood ratio test comparing full-null model comparison: $\chi^{2}=10.70$, df $=2, p=0.005$; Table VId), suggesting that tsaks given by AL individuals were noisier than those given by CR individuals (Fig. 3).

\section{Discussion}

We have shown in this study that mouse lemurs under caloric restriction had a lower body mass than individuals under the ad libitum diet, suggesting that they were in poorer body condition than individuals under the ad libitum diet. In grunts, the $1^{\text {st }}$ element was characterized by more energy in higher frequencies than the $2^{\text {nd }}$ element. Body mass correlated negatively with both principal components, with heavier individuals producing lower-frequency grunts. Accordingly, AL individuals 


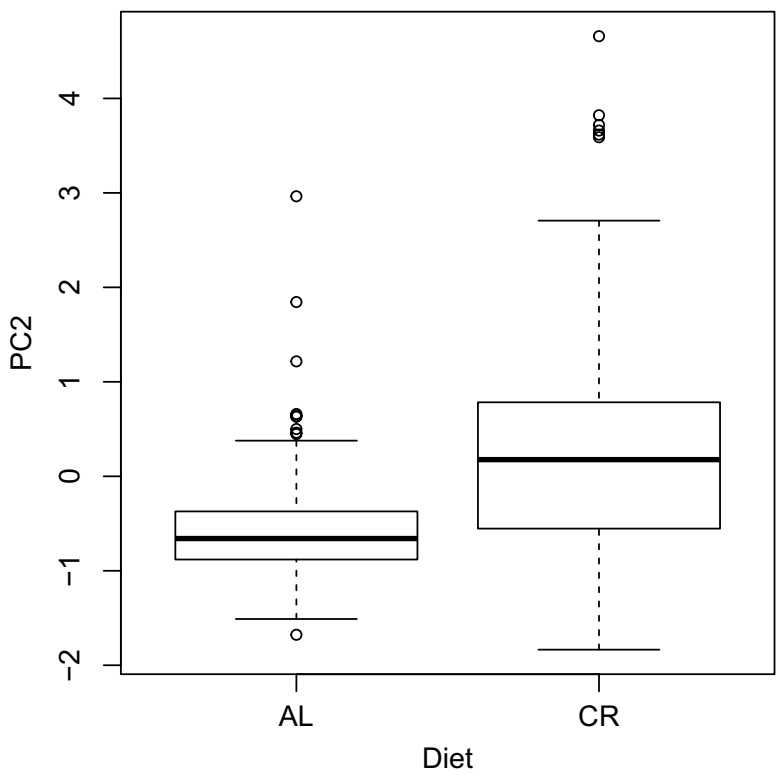

Figure 3 PC2 $\left(2^{\text {nd }}\right.$ principal component $)$ of tsaks recorded in a study of mouse lemur vocalizations housed at the CNRS, MNHN, Brunoy (2010) as a function of dietary regimes ( $A L=$ ad libitum, $C R=$ caloric restriction). Depicted are boxplots showing medians (solid lines), inter-quartile ranges (boxes), ranges (whiskers) and outliers (open circles) of PC2.

produced lower-frequency grunts than CR individuals. Acoustic features of tsaks were predicted by neither body mass nor sex. However, tsaks produced by AL individuals were noisier than those produced by CR individuals. Noisiness in vocalizations has been suggested to be associated with aggressiveness, suggesting that mouse lemurs in comparatively better condition might have been able to afford to be more aggressive. Hence, manipulation of body condition via dietary regimes affected acoustic features of calls given during aggression in different ways: acoustic features of grunts varied according to the rule of acoustic allometry similar to what has been proposed for many other species. Acoustic features of tsaks, however, varied according to motivational structural rules.

\section{Grunts}

Grunts consist of two elements that differ in distribution of energy, with the $1^{\text {st }}$ element having more energy in higher frequencies than the $2^{\text {nd }}$ element. Body mass correlated negatively with the distribution of energy in both elements, with heavier individuals producing lower-frequency grunts. These results are in line with the rule for acoustic allometry, supporting earlier studies in many other species (Bowling et al. 2017; Charlton and Reby 2016; Fitch and Hauser 1995; Garcia et al. 2018; Gingras et al. 2013; Hauser 1993; Wallschläger 1980). Although many studies have focused on fundamental frequency or 
formant dispersion to assess acoustic allometry (Fitch 1997; Fitch and Hauser 1995; Fitch and Reby 2001), a more recent comparative study revealed that the frequency with the highest amplitude also co-varies with body mass in carnivores and primates (Bowling et al. 2017). Here, we show that a general shift in frequencies, summarized as principal components, also co-varies with body mass in mouse lemur grunts.

In grey mouse lemurs in the wild, body mass predicts several fitness proxies such as survival (Hämäläinen et al. 2014; Rakotoniaina et al. 2017), the ability to cope better with environmental constraints through physiological mechanisms, such as torpor (Vuarin et al. 2013) or allostatic load in males (Hämäläinen et al. 2015), reproductive success in males (Eberle and Kappeler 2004b), and the relative proportion of polyandrous mating in females in captivity (Huchard et al. 2012). Hence, acoustic features that convey information about body mass might serve as honest signals (Zahavi 1977). Similarly, call rates of mouse lemur trills that are produced in the mating season to attract mates have been suggested to be associated with rank and to advertise quality (Zimmerman 1996). Hence, both calling rates of advertisement calls and acoustic features of aggressive grunts may serve to advertise quality in mouse lemurs.

Mouse lemurs may benefit from signaling their current body condition during agonistic interactions, in particular. During the mating season, males roam widely in search of receptive females by enlarging their home ranges to cover the center of activity of up to 21 females (Eberle and Kappeler, 2004a). Once they encounter an estrous female, they attempt to mate-guard her by staying close to her and trying to fend off rivals. An estrous female is usually guarded by several males, and the longer a male can guard a female, the fewer mating partners she has. During mate-guarding, males fight with several other males, and male mortality increases during the brief mating season because of this risky mating strategy (Kraus et al. 2008). In addition, in captivity females preferentially accepted copulations from more competitive, aggressive males (Gomez et al. 2012). Hence, males clearly benefit from signaling condition and fighting ability in vocalizations, both during agonistic interactions with rivals and to obtain access to matings.

In contrast, females may face male harassment during the mating season. They are receptive for only one night, but males harass and inspect females' reproductive state over the whole mating season (Eberle and Kappeler 2004a). In addition, estrous females are guarded by several males but may try to escape guarding males (Eberle and Kappeler 2004a) to mate with other males (Huchard et al. 2012). Hence, signaling their condition during such conflicts might also be beneficial for females. Outside the mating season, both males and females produce grunts during aggressive interactions and during disturbances at the sleeping site (Radespiel and Zimmermann 2001, Zimmermann 2010). In both contexts, individuals might benefit from signaling condition and fighting ability. Playback experiments are now required to determine whether mouse lemurs also respond to acoustic cues indicating differently sized callers, as in other species (Reby et al. 2005; Charlton et al. 2010b). 


\section{Tsaks}

In contrast to grunts, acoustic features of tsaks did not correlate with body mass. Neither shifts in the general energy distribution nor the mean fundamental frequency co-varied with body mass. Tsaks have a relatively a narrow frequency bandwidth, with little variation across calls. Their mean central frequency, for example, varied on average only by about $2 \mathrm{kHz}$, whereas the mean central frequency in grunts varied by about $5 \mathrm{kHz}$. Hence, the production of tsaks may be too constrained to co-vary with changes in body mass. Unfortunately, we could only measure the fundamental frequency in a subset of calls, and the lack of a significant correlation between fundamental frequency and body mass might be due to the small sample size. Additional recordings are required to understand whether acoustic features of tsaks co-vary principally with body mass, for example during the development from infancy to adulthood.

Dietary treatment predicted the amount of noisy energy in tsaks. Individuals on the ad libitum diet produced noisier calls than caloric-restricted individuals. According to the motivational-structural rules (Morton 1977), noisiness is associated with aggression. More aggressive calls are, for example, characterized by noisier acoustic structure in squirrel monkeys (Saimiri sciureus) and Geoffroy's spider monkeys (Ateles geoffoyi) (Fichtel et al. 2001; Ordóñez-Gómez et al. 2015). Since mouse lemurs on the ad libitum dietary regime were in better condition, they might have been able to afford to be more aggressive, and hence produced more noisy calls. Moreover, in another study including some females that also participated in this study, caloric-restricted females mated only with one male, whereas females on the ad libitum dietary regime mated with several males (Huchard et al. 2012). Since mating is costly and body mass loss during mating correlated with the number of mating partners (Huchard et al. 2012), caloric-restricted females might be less likely to engage in energetic costly aggressive behavior during disturbances.

Vocalizations that contain more nonlinear dynamics, such as noise, have been suggested to be more unpredictable, and this unpredictability may function to prevent receivers from ignoring such calls (Fitch and Hauser 1995; Fitch et al. 2002). Playback experiments revealed that yellow-bellied marmots (Marmota flaviventris) responded more strongly to alarm calls including noise than to control calls, supporting the notion that the adaptive value of non-linearities might be to prevent habituation (Blumstein and Récapet 2009). Again, playback experiments are required to examine whether mouse lemurs also respond more strongly to noisier tsaks. In principle, signaling condition or the motivational state is beneficial both during competition over mates and to defend resources such as feeding or sleeping sites or to deter predators, contexts in which both call types are produced (Eberle and Kappeler 2008; Rahlfs and Fichtel 2010; Zimmermann 2010).

Finally, variation in acoustic features can also be due to group membership or relatedness (Mitani et al. 1992; Levréro et al. 2015). However, we think it is unlikely that group membership or relatedness explains variation in acoustic features across dietary regimes, because only a few dyads of mouse lemurs were closely related in our study, and individuals were either housed individually or were recorded only from individuals of different groups if they were housed in groups. 
In conclusion, manipulation of body condition via dietary regimes affected acoustic features of calls given during aggression in different ways: mouse lemurs in better condition produced lower-pitched grunts than those in weaker condition, supporting the rule of acoustic allometry. In contrast, the acoustic features of tsaks did not support the rule of acoustic allometry but did follow motivational structural rules. Mouse lemurs in better condition might have been able to show more aggression and produced more noisy calls. However, we only compared vocalizations of different individuals in which body mass was manipulated via caloric restriction. Since mouse lemurs undergo seasonal changes of up one third of their body mass in their natural habitat (Hämäläinen et al. 2014), a longitudinal study is needed to examine how changes in body mass within individuals are also reflected in the acoustic structure of aggressive vocalizations. This would also allow us to investigate whether acoustic cues indicate stable, long-term attributes of callers as well as more flexible variation in condition and, hence, fighting ability.

Acknowledgements This paper is dedicated to Elke Zimmermann, a pioneer in the study of communication in nocturnal primates. We are very grateful to Ute Radespiel and Marina Scheumann for the invitation to contribute to the Festschrift for Elke Zimmermann. Financial support was obtained from UMR 7179 CNRS MNHN, and a PEPS 2009 grant attributed to PYH by INEE-CNRS. EH was funded by a Deutsches Forschungsgemeinschaft (DFG) research grant (no HU 1820/1-1).

Author Contributions CF conceived, designed, and executed this study. MP, EH, P-YH were responsible for animal housing and conducting the caloric restriction experiment. CF and PMK wrote the manuscript; other authors provided editorial advice.

Funding Open Access funding enabled and organized by Projekt DEAL.

Open Access This article is licensed under a Creative Commons Attribution 4.0 International License, which permits use, sharing, adaptation, distribution and reproduction in any medium or format, as long as you give appropriate credit to the original author(s) and the source, provide a link to the Creative Commons licence, and indicate if changes were made. The images or other third party material in this article are included in the article's Creative Commons licence, unless indicated otherwise in a credit line to the material. If material is not included in the article's Creative Commons licence and your intended use is not permitted by statutory regulation or exceeds the permitted use, you will need to obtain permission directly from the copyright holder. To view a copy of this licence, visit http://creativecommons.org/licen ses/by/4.0/.

\section{References}

Animal Behaviour (2020). Guidelines for the treatment of animals in behavioural research and teaching. Animal Behaviour, 159, I-XI. https://doi.org/10.1006/anbe.1996.0293

Arnott, G., \& Elwood, R. W. (2009). Assessment of fighting ability in animal contests. Animal Behaviour, 77, 991-1004. https://doi.org/10.1016/j.anbehav.2009.02.010

Aujard, F., Perret, M., \& Vanier, G. (1998). Thermoregulatory responses to variations of photoperiod and ambient temperature in the lesser mouse lemur: a primitive or an advanced adaptive character? Journal of Comparative Physiology B, 168, 540-548. https://doi.org/10.1007/s003600050175

Barelli, C., Mundry, R., Heistermann, M., \& Hammerschmidt, K. (2013). Cues to androgens and quality in male gibbon songs. PLoS ONE, 8, e82748-e82749. https://doi.org/10.1371/journal.pone.0082748

Barr, D. J., Levy, R., Scheepers, C., \& Tily, H. J. (2013). Random effects structure for confirmatory hypothesis testing: Keep it maximal. Journal of Memory and Language, 68, 255-278. https://doi. org/10.1016/j.jml.2012.11.001 
Bates, D., Mächler, M., Bolker, B., \& Walker, S. (2015). Fitting linear mixed-effects models using lme4. Journal of Statistical Software, 67, 1-48 https://www.jstatsoft.org/article/view/v067i01

Blumstein, D. T., \& Récapet, C. (2009). The sound of arousal: the addition of novel non-linearities increases responsiveness in marmot alarm calls. Ethology, 115, 1074-1081. https://doi.org/10. 1111/j.1439-0310.2009.01691.x

Bowling, D. L., Garcia, M., Dunn, J. C., Ruprecht, R., Stewart, A., Frommolt, K. H., \& Fitch, W. T. (2017). Body size and vocalization in primates and carnivores. Scientific Reports, 7, 41070 https:// www.nature.com/articles/srep41070

Bradbury, J. W., \& Vehrencamp, S. L. (2011). Principles of animal communication (2nd ed.). Sinauer.

Buesching, C. D., Heistermann, M., Hodges, J. K., \& Zimmermann, E. (1998). Multimodal oestrus advertisement in a small nocturnal prosimian, Microcebus murinus. Folia Primatologica, 69, 295308. https://doi.org/10.1159/000052718

Canale, C. I., Perret, M., Thiéry, M., \& Henry, P.-Y. (2011). Physiological flexibility and acclimation to food shortage in a heterothermic primate. Journal of Experimental Biology, 214, 551-560 https:// jeb.biologists.org/content/214/4/551

Chajewski, M. (2009). rela: Scale item analysis. $R$ package version, $4,1$.

Charlton, B. D., Zhihe, Z., \& Snyder, R. J. (2009). The information content of giant panda, Ailuropoda melanoleuca, bleats: acoustic cues to sex, age and size. Animal Behaviour, 78, 893-898. https://doi. org/10.1016/j.anbehav.2009.06.029

Charlton, B. D., Keating, J. L., Rengui, L., Huang, Y., \& Swaisgood, R. R. (2010a). Female giant panda (Ailuropoda melanoleuca) chirps advertise the caller's fertile phase. Proceedings of the Royal Society B: Biological Sciences, 277, 1101-1106. https://doi.org/10.1098/rspb.2009.1431

Charlton, B. D., Zhihe, Z., \& Snyder, R. J. (2010b). Giant pandas perceive and attend to formant frequency variation in male bleats. Animal Behaviour, 79, 1221-1227. https://doi.org/10.1016/j.anbeh av.2010.02.018

Charlton, B. D., \& Reby, D. (2016). The evolution of acoustic size exaggeration in terrestrial mammals. Nature Communication, 7, 12739. https://doi.org/10.1038/ncomms12739

Charlton, B. D., Pisanski, K., Raine, J., \& Reby, D. (2020). Coding of static information in terrestrial mammal vocal signals. In Coding Strategies in Vertebrate Acoustic Communication (Vol. 7, pp. 115-136). Cham: Springer International Publishing.

Seyfarth, R. M., \& Cheney, D. L. (2003). Signalers and receivers in animal communication. Annual Review of Psychology, 54, 145-173.

Clarke, E., Reichard, U. H., Zuberbühler, K., \& Emery, N. (2006). The syntax and meaning of wild gibbon songs. PLoS ONE, 1, e73. https://doi.org/10.1371/journal.pone.0000073

Dal-Pan, A., Terrien, J., Pifferi, F., Botalla, R., Hardy, I., Marchal, J., Zahariev, A., Chery, I., Zizzari, P., Perret, M., Picq, J. L., Epelbaum, J., Blanc, S., \& Aujard, F. (2011). Caloric restriction or resveratrol supplementation and ageing in a non-human primate: first-year outcome of the RESTRIKAL study in Microcebus murinus. Age (Dordrecht, Netherlands), 33, 15-31. https://doi.org/10.1007/ s11357-010-9156-6

Dammhahn, M., \& Kappeler, P. M. (2008). Small-scale coexistence of two mouse lemur species (Microcebus berthae and M. murinus) within a homogeneous competitive environment. Oecologia, 157, 473-483. 10.1007\%2Fs00442-008-1079-X

Dewar, R. E., \& Richard, A. F. (2007). Evolution in the hypervariable environment of Madagascar. Proceedings of the National Academy of Sciences of the United States of America, 104, 13723-13727. https://doi.org/10.1073/pnas.0704346104

Dunn, J. C., Halenar, L. B., Davies, T. G., Cristobal-Azkarate, J., Reby, D., Sykes, D., Dengg, S., Fitch, W. T., \& Knapp, L. A. (2015). Evolutionary trade-off between vocal tract and testes dimensions in howler monkeys. Current Biology, 25, 2839-2844 https://www.sciencedirect.com/science/article/ pii/S0960982215011094

Eberle, M., \& Kappeler, P. M. (2004a). Selected polyandry: female choice and inter-sexual conflict in a small nocturnal solitary primate (Microcebus murinus). Behavioral Ecology and Sociobiology, 57, 91-100. https://doi.org/10.1007/s00265-004-0823-4

Eberle, M., \& Kappeler, P. M. (2004b). Sex in the dark: determinants and consequences of mixed male mating tactics in Microcebus murinus, a small solitary nocturnal primate. Behavioral Ecology and Sociobiology, 57, 77-90. https://doi.org/10.1007/s00265-004-0826-1

Eberle, M., \& Kappeler, P. M. (2008). Mutualism, reciprocity, or kin selection? Cooperative rescue of a conspecific from a boa in a nocturnal solitary forager the gray mouse lemur. American Journal of Primatology, 70, 410-414. https://doi.org/10.1002/ajp.20496 
Ey, E., Hammerschmidt, K., Seyfarth, R. M., \& Fischer, J. (2007). Age- and sex-related variations in clear calls of Papio ursinus. International Journal of Primatology, 28(4), 947-960. https://doi.org/ 10.1007/s10764-007-9139-3

Fichtel, C. (2014). Acoustic differences in loud calls of Decken's and crowned sifakas (Propithecus deckenii and $P$. coronatus) at two sites in Madagascar, 1-7. https://doi.org/10.1896/052.028.0105

Fichtel, C., Hammerschmidt, K., \& Jürgens, U. (2001). On the expression of emotion. A multi-parametric analysis of different states of aversion in the squirrel monkey. Behaviour, 138, 97-116. https://doi. org/10.1163/15685390151067094

Fichtel, C., \& Hammerschmidt, K. (2002). Responses of redfronted lemurs to experimentally modified alarm calls: evidence for urgency-based changes in call structure. Ethology, 108, 763-777. https://doi.org/10.1046/j.1439-0310.2002.00816.x

Fichtel, C., \& Hammerschmidt, K. (2003). Responses of squirrel monkeys to their experimentally modified mobbing calls. The Journal of the Acoustical Society of America, 113(5), 2927-2932. https://doi.org/10.1121/1.1548158

Fichtel, C., Perry, S., \& Gros Louis, J. (2005). Alarm calls of white-faced capuchin monkeys: an acoustic analysis. Animal Behaviour, 70, 165-176. https://doi.org/10.1016/j.anbehav.2004.09. 020

Fischer, J., Kitchen, D. M., Seyfarth, R. M., \& Cheney, D. L. (2004). Baboon loud calls advertise male quality: acoustic features and their relation to rank, age, and exhaustion. Behavioral Ecology and Sociobiology, 56, 140-148. https://doi.org/10.1007/s00265-003-0739-4

Fitch, W. (1997). Vocal tract length and formant frequency dispersion correlate with body size in rhesus macaques. The Journal of the Acoustical Society of America., 102, 1213. https://doi.org/10. $1121 / 1.421048$

Fitch, W. T., \& Hauser, M. D. (1995). Vocal production in nonhuman primates: acoustics, physiology, and functional constraints on "honest" advertisement. American Journal of Primatology, 37, 191-219. https://doi.org/10.1002/ajp.1350370303

Fitch, T. W., \& Reby, D. (2001). The descended larynx is not uniquely human. Proceedings of the Royal Society of London. Series B: Biological Sciences, 268, 1669-1675. https://doi.org/10. 1098/rspb.2001.1704

Fitch, W. T., Neubauer, J., \& Herzel, H. (2002). Calls out of chaos: the adaptive significance of nonlinear phenomena in mammalian vocal production. Animal Behaviour, 63, 407-418. https://doi. org/10.1006/anbe.2001.1912

Forstmeier, W., \& Schielzeth, H. (2011). Cryptic multiple hypotheses testing in linear models: overestimated effect sizes and the winner's curse. Behavioral Ecology \& Sociobiology, 65, 47-55. https://doi.org/10.1007/s00265-010-1038-5

Fox, J., \& Weisberg, S. (2019). An R Companion to Applied Regression (Third ed.). Sage https://socia lsciences.mcmaster.ca/jfox/Books/Companion/

Garcia, M., Herbst, C. T., Bowling, D. L., Dunn, J. C., \& Fitch, W. T. (2018). Acoustic allometry revisited: morphological determinants of fundamental frequency in primate vocal production. Scientific Reports, 7, 10450 https://www.nature.com/articles/s41598-017-11000-x

Gingras, B., Boeckle, M., Herbst, C. T., \& Fitch, W. T. (2013). Call acoustics reflect body size across four clades of anurans. Journal of Zoology, 289, 143-150. https://doi.org/10.1111/j.1469-7998. 2012.00973.x

Giroud, S., Blanc, S., Aujard, F., Bertrand, F., Gilbert, C., \& Perret, M. (2008). Chronic food shortage and seasonal modulations of daily torpor and locomotor activity in the grey mouse lemur (Microcebus murinus). American Journal of Physiology Regulatory Integrative and Comparative Physiology, 294, R1958-R1967. https://doi.org/10.1152/ajpregu.00794.2007

Gomez, D., Huchard, E., Henry, P.-Y., \& Perret, M. (2012). Mutual mate choice in a female-dominant and sexually monomorphic primate. American Journal of Physical Anthropology, 147, 370-379. https://doi.org/10.1002/ajpa.21653

Hauser, M. D. (1993). The evolution of nonhuman primate vocalizations: effects of phylogeny, body weight, and social context. The American Naturalist, 142, 528-542. https://doi.org/10.1086/ 285553

Hämäläinen, A., Dammhahn, M., Aujard, F., Eberle, M., Hardy, I., Kappeler, P. M., Perret, M., SchlieheDiecks, S., \& Kraus, C. (2014). Senescence or selective disappearance? Age trajectories of body mass in wild and captive populations of a small-bodied primate. Proceedings of the Royal Society B: Biological Sciences, 281, 20140830. https://doi.org/10.1098/rspb.2014.0830 
Hämäläinen, A., Heistermann, M., \& Kraus, C. (2015). The stress of growing old: sex-and season-specific effects of age on allostatic load in wild grey mouse lemurs. Oecologia, 178, 1063-1075. https:// doi.org/10.1007/s00442-015-3297-3

Huchard, E., Canale, C. I., Le Gros, C., Perret, M., Henry, P.-Y., \& Kappeler, P. M. (2012). Convenience polyandry or convenience polygyny? Costly sex under female control in a promiscuous primate. Proceedings of the Royal Society B: Biological Sciences, 279, 1371-1379. https://doi.org/10.1098/ rspb.2011.1326

Jennions, M. D., \& Petrie, M. (2000). Why do females mate multiply? A review of the genetic benefits. Biological Reviews, 75, 21-64. https://doi.org/10.1111/j.1469-185X.1999.tb00040.x

Jonart, L. M., Hill, G. E., \& Badyaev, A. V. (2007). Fighting ability and motivation: determinants of dominance and contest strategies in females of a passerine bird. Animal Behaviour, 74(6), 1675-1681 https://www.sciencedirect.com/science/article/abs/pii/S0003347207003144

Kitchen, D., Seyfarth, R., Fischer, J., \& Cheney, D. (2003). Loud calls as indicators of dominance in male baboons (Papio cynocephalus ursinus). Behavioral Ecology and Sociobiology, 53, 374-385. https:// doi.org/10.1007/s00265-003-0588-1

Kraus, C., Eberle, M., \& Kappeler, P. M. (2008). The costs of risky male behaviour: sex differences in seasonal survival in a small sexually monomorphic primate. Proceedings of the Royal Society London B, 275, 1635-1644. https://doi.org/10.1098/rspb.2008.0200

Kuznetsova, A., Brockhoff, P. B., \& Christensen, R. H. B. (2017). lmerTest Package: Tests in Linear Mixed Effects Models. Journal of Statistical Software, 82, 1-26. https://doi.org/10.18637/jss.v082. i13

Leliveld, L. M., Scheumann, M., \& Zimmermann, E. (2011). Acoustic correlates of individuality in the vocal repertoire of a nocturnal primate (Microcebus murinus). The Journal of the Acoustical Society of America, 129, 2278-2288. https://doi.org/10.1121/1.3559680

Levréro, F., Carrete-Vega, G., Herbert, A., Lawabi, I., Courtiol, A., Willaume, E., Kappeler, P. M., \& Charpentier, M. J. E. (2015). Social shaping of voices does not impair phenotype matching of kinship in mandrills. Nature Communications, 6, 1-7 https://www.nature.com/articles/ncomms8609? origin $=$ ppub

Manser, M. (2001). The acoustic structure of suricates' alarm calls varies with predator type and the level of response urgency. Proceedings of the Royal Society London B, 268, 2315-2324. https://doi.org/ 10.1098/rspb.2001.1773

Masters, W. M., Raver, K. A. S., \& Kazial, K. A. (1995). Sonar signals of big brown bats, Eptesicus fuscus, contain information about individual identity, age and family affiliation. Animal Behaviour, 50, 1243-1260. https://doi.org/10.1016/0003-3472(95)80041-7

Mitani, J. C., Hasegawa, T., Gros-Louis, J., Marler, P., \& Byrne, R. (1992). Dialects in wild chimpanzees? American Journal of Primatology, 27, 233-243. https://doi.org/10.1002/ajp.1350270402

Morton, E. S. (1977). On the occurrence and significance of motivation-structural rules in some bird and mammal sounds. American Naturalist, 111, 855-869 https://www.jstor.org/stable/2460385

Nieuwenhuis, R., te Grotenhuis, M., \& Pelzer, B. (2012). Influence.me: Tools for detecting influential data in mixed effects models. The R Journal, 4, 38-47 https://journal.r-project.org/archive/2012/RJ2012-011/index.html

Ordóñez-Gómez, J. D., Dunn, J. C., Arroyo-Rodríguez, V., Méndez-Cárdenas, M. G., Márquez-Arias, A., \& Santillán-Doherty, A. M. (2015). Role of emitter and severity of aggression influence the agonistic vocalizations of Geoffroy's spider monkeys (Ateles geoffroyi). International Journal of Primatology, 36(2), 429-440. https://doi.org/10.1007/s10764-015-9833-5

Perneger, T. V. (1998). What's wrong with Bonferroni adjustments. BMJ, 316(7139), 1236-1238. https:// doi.org/10.1136/bmj.316.7139.1236

Perret, M., \& Aujard, F. (2001). Regulation by photoperiod of seasonal changes in body mass and reproductive function in gray mouse lemurs (Microcebus murinus): differential responses by sex. International Journal of Primatology, 22, 5-24. https://doi.org/10.1023/A:1026457813626

Puts, D. A., Hill, A. K., Bailey, D. H., Walker, R. S., Rendall, D., Wheatley, J. R., et al (2016). Sexual selection on male vocal fundamental frequency in humans and other anthropoids. Proceedings of the Royal Society London B, 283, 20152830-20152838. https://doi.org/10.1098/rspb.2015.2830

Queen, J. P., Quinn, G. P., \& Keough, M. J. (2002). Experimental design and data analysis for biologists. Cambridge,UK: Cambridge University Press.

R Core Team. (2020). R: A Language and Environment for Statistical Computing. Vienna, Austria: R Foundation for Statistical Computing 
Radespiel, U. (2000). Sociality in the gray mouse lemur (Microcebus murinus) in northwestern Madagascar. American Journal of Primatology, 51, 21-40. https://doi.org/10.1002/(SICI)1098-2345(200005) 51:121::AID-AJP33.0.CO;2-C

Radespiel, U., \& Zimmermann, E. (2001). Female dominance in captive gray mouse lemurs (Microcebus murinus). American Journal of Primatology, 54, 181-192. https://doi.org/10.1002/ajp.1029

Rahlfs, M. \& Fichtel, C. (2010). Anti-predator behaviour in a nocturnal primate, the grey mouse lemur (Microcebus murinus). Ethology, 116, 429-439. https://doi.org/10.1111/j.1439-0310.2010.01756.x

Rakotoniaina, J. H., Kappeler, P. M., Kaesler, E., Hämäläinen, A. M., Kirschbaum, C., \& Kraus, C. (2017). Hair cortisol concentrations correlate negatively with survival in a wild primate population. BMC ecology, 1-13. https://doi.org/10.1186/s12898-017-0140-1

Reby, D., \& McComb, K. (2003). Anatomical constraints generate honesty: acoustic cues to age and weight in the roars of red deer stags. Animal Behaviour, 65, 519-530. https://doi.org/10.1006/anbe. 2003.2078

Reby, D., McComb, K., Cargnelutti, B., Darwin, C., Fitch, W., \& Clutton-Brock, T. (2005). Red deer stags use formants as assessment cues during intrasexual agonistic interactions. Proceedings of the Royal Society London B, 272, 941. https://doi.org/10.1098/rspb.2004.2954

Rendall, D., Rodman, P. S., \& Emond, R. E. (1996). Vocal recognition of individuals and kin in freeranging rhesus monkeys. Animal Behaviour, 51, 1007-1015. https://doi.org/10.1006/anbe.1996. 0103

Ryan, M. J., \& Brenowitz, E. A. (1985). The role of body size, phylogeny, and ambient noise in the evolution of bird song. American Naturalist, 87-100 https://www.jstor.org/stable/2461564

Scheumann, M., Zimmermann, E., \& Deichsel, G. (2007). Context-specific calls signal infants' needs in a strepsirrhine primate, the gray mouse lemur (Microcebus murinus). Developmental Psychobiology, 49, 708-718. https://doi.org/10.1002/dev.20234

Schielzeth, H., \& Forstmeier, W. (2009). Conclusions beyond support: overconfident estimates in mixed models. Behavioral Ecology, 20, 416-420. https://doi.org/10.1093/beheco/arn145

Schmid, J., \& Kappeler, P. M. (1998). Fluctuating sexual dimorphism and differential hibernation by sex in a primate, the gray mouse lemur (Microcebus murinus). Behavioral Ecology and Sociobiology, 43, 125-132. https://doi.org/10.1007/s002650050474

Schrader, L., \& Hammerschmidt, K. (1997). Computer-aided analysis of acoustic parameters in animal vocalisations: a multi-parametric approach. Bioacoustics, 7, 247-265. https://doi.org/10.1080/09524 622.1997 .9753338

Semple, S., Mccomb, K., Alberts, S., \& Altmann, J. (2002). Information content of female copulation calls in yellow baboons. American Journal of Primatology, 56, 43-56. https://doi.org/10.1002/ajp. 1062

Taylor, A., \& Reby, D. (2010). The contribution of source-filter theory to mammal vocal communication research. Journal of Zoology, 280, 221-236. https://doi.org/10.1111/j.1469-7998.2009.00661.x

Vannoni, E., \& McElligott, A. G. (2008). Low frequency groans indicate larger and more dominant fallow deer (Dama dama) males. PloS One, 3, e3113. https://doi.org/10.1371/journal.pone.0003113

Vieira, M. C., \& Peixoto, P. E. (2013). Winners and losers: a meta-analysis of functional determinants of fighting ability in arthropod contests. Functional Ecology, 27(2), 305-313.

Vuarin, P., Dammhahn, M., \& Henry, P.-Y. (2013). Individual flexibility in energy saving: body size and condition constrain torpor use. Functional Ecology, 27, 793-799. https://doi.org/10.1111/13652435.12069

Wallschläger, D. (1980). Correlation of song frequency and body weight in passerine birds. Experientia, 36, 412. https://doi.org/10.1007/BF01975119

Zahavi, A. (1977). The cost of honesty (further remarks on the handicap principle). Journal of Theoretical Biology, 67, 603-605. https://doi.org/10.1016/0022-5193(77)90061-3

Zimmermann, E. (1996). Castration affects the emission of an ultrasonic vocalization in a nocturnal primate, the grey mouse lemur (Microcebus murinus). Physiology \& Behavior, 60, 693-697. https:// doi.org/10.1016/0031-9384(96)81674-X

Zimmermann, E., Vorobieva, E., Wrogemann, D., \& Hafen, T. (2000). Use of vocal fingerprinting for specific discrimination of gray (Microcebus murinus) and rufous mouse lemurs (Microcebus rufus). International Journal of Primatology, 21, 837-852. https://doi.org/10.1023/A:1005594625841

Zimmermann, E. (2010). Vocal expression of emotion in a nocturnal prosimian primate group, mouse lemurs. In S. M. Brudzynski (Ed.), Handbook of Mammalian Vocalization: An Integrative Neuroscience Approach (pp. 215-226). Academic Press. 


\section{Authors and Affiliations}

\section{Claudia Fichtel $^{1,2}$ D $\cdot$ Peter M. Kappeler ${ }^{1,3} \cdot$ Martine Perret $^{4} \cdot$ Elise Huchard $^{5}$. Pierre-Yves Henry ${ }^{4}$}

1 Behavioral Ecology \& Sociobiology Unit, German Primate Center, Leibniz Institute for Primate Research, Kellnerweg 4, 37077 Göttingen, Germany

2 Leibniz-Science Campus Primate Cognition, Göttingen, Germany

3 Department of Sociobiology/Anthropology, Johann-Friedrich-Blumenbach Institute of Zoology and Anthropology, Georg-August Universität, Göttingen, Germany

4 Mécanismes Adaptatifs et Evolution (MECADEV - UMR 7179), CNRS, MNHN, Brunoy, France

5 Institute of Evolutionary Biology of Montpellier (ISEM), Université de Montpellier, CNRS, Montpellier, France 